\title{
Spatiotemporal analysis of nitrogen cycling in a mixed coniferous forest of the northern United States
}

\author{
I. Howard ${ }^{1}$ and K. K. McLauchlan ${ }^{2}$ \\ ${ }^{1}$ Department of Geosciences, University of Arkansas, 216 Ozark Hall, Fayetteville, AR 72701, USA \\ ${ }^{2}$ Department of Geography, Kansas State University, 118 Seaton Hall, Manhattan, KS 66506, USA \\ Correspondence to: I. Howard (ihowardksu@gmail.com)
}

Received: 26 January 2015 - Published in Biogeosciences Discuss.: 27 February 2015

Revised: 22 May 2015 - Accepted: 26 May 2015 - Published: 01 July 2015

\begin{abstract}
Nitrogen $(\mathrm{N})$ is the limiting nutrient to primary productivity in a variety of temperate forests, and $\mathrm{N}$ cycling is undergoing a variety of anthropogenic changes, notably a doubling of reactive $\mathrm{N}(\mathrm{Nr})$ on a global scale. Yet, the magnitude of these changes to $\mathrm{N}$ cycling has been difficult to document in terrestrial ecosystems, especially in old-growth forests. To determine the trajectory of $\mathrm{N}$ cycling and the potential impacts of anthropogenic influences at local scales, we measured the composition of stable nitrogen isotopes $\left(\delta^{15} \mathrm{~N}\right)$ in wood from living red pine trees (Pinus resinosa) at a single site in northern Minnesota, USA. A synchronous decline in wood $\delta^{15} \mathrm{~N}$ values began approximately in the 1920s in 17 individual trees at different topographic positions, indicating a common driver. The decline in wood $\delta^{15} \mathrm{~N}$ values corresponded with declines in sedimentary $\delta^{15} \mathrm{~N}$ recorded in lacustrine sediments of the same catchment. Disturbance regime and species composition began to change at the turn of the 20th century with park establishment, providing a likely mechanism of decline in $\delta^{15} \mathrm{~N}$ values toward present. While other mechanisms of this change are possible, we conclude that while there may be consequences of increased influxes of various forms of anthropogenic $\mathrm{Nr}$ into terrestrial ecosystems at the global level, these changes are not being expressed at a local level in this temperate forest ecosystem.
\end{abstract}

\section{Introduction}

Global biogeochemical cycles have been altered by human activities, such as elevated levels of atmospheric $\mathrm{CO}_{2}$, global increases in temperatures, and increased deposition of reactive nitrogen (Nr) through anthropogenic sources (fossil fuel burning and fertilizer production; Vitousek et al., 1997). In forested ecosystems, increases in atmospheric nitrogen $(\mathrm{N})$ deposition have been of particular concern, because a variety of negative environmental consequences, such as reduced forest growth, eutrophication, acid rain, and biodiversity loss, have been attributed to increases in $\mathrm{Nr}$ (Hietz et al., 2011; Houlton et al., 2013). Despite global-scale changes to N cycling, it has been difficult to pinpoint effects of $\mathrm{Nr}$ on a local scale in terrestrial ecosystems, due to an additional suite of activities that affect local $\mathrm{N}$ cycling such as management practices, intensive logging, disturbance regimes, alteration of species composition, and regional-scale variability in climate (Kareiva et al., 2007; McLauchlan and Craine, 2012).

Although understanding how these factors affect the $\mathrm{N}$ cycle is of paramount importance to understanding recent changes in forest dynamics, long-term records of $\mathrm{N}$ cycling in forests are rare and generally restricted to modern measurements that might span a few decades at most (Gerhart and McLauchlan, 2014). Long-term monitoring of $\mathrm{N}$ cycling metrics such as stream nitrate export indicates an unexpected ability of many terrestrial ecosystems to retain added $\mathrm{N}$, with stable or declining trends in $\mathrm{N}$ availability since monitoring began in the late 20th century (Bernal et al., 2012). A more temporally complete understanding of the modern state and trajectory of $\mathrm{N}$ cycling in forests requires extending records back in time prior to settlement by Euro-Americans (Galloway et al., 2004). This retrospective approach, which 
uses $\mathrm{N}$ cycling proxies preserved in wood or sedimentary archives, has supported and extended the long-term monitoring studies. Some retrospective studies have indicated that regional and local-scale processes may be altering $\mathrm{N}$ availability to varying degrees during the past 500 years (McLauchlan et al., 2013a).

While our understanding of $\mathrm{N}$ availability in terrestrial ecosystems has improved, the lack of long-term records and relatively poor spatial coverage limits the ability to fully assess the consequences of anthropogenic disturbance to the $\mathrm{N}$ cycle. Retrospective analyses of biogeochemical cycling provides a unique opportunity to assess natural variability of many elemental cycles. Given that humans have altered, and in many cases increased, the fluxes between major pools of elements, it is important to develop records that document the behavior of these cycles on various spatial scales prior to and following human disturbance. Fortunately, analysis of the standardized natural abundance ratios of ${ }^{15} \mathrm{~N}$ to ${ }^{14} \mathrm{~N}$ $\left(\delta^{15} \mathrm{~N}\right)$ stored in tree rings is a relatively new technique that serves as a proxy record for the history of $\mathrm{N}$ availability in past terrestrial ecosystems (Gerhart and McLauchlan, 2014). Of the approximately 50 published wood $\delta^{15} \mathrm{~N}$ studies so far, the majority have been in secondary forests, with trees less than a century old (e.g., Poulson et al., 1995; Bukata and Kyser, 2007; Hietz et al., 2010; Beghin et al., 2011; Stock et al., 2012; McLauchlan and Craine, 2012). The oldest published wood $\delta^{15} \mathrm{~N}$ value is from a sample dated to $1835 \mathrm{CE}$ (McLauchlan et al., 2007). Because secondary forests are accruing biomass, with high demand for $\mathrm{N}$, these types of sites potentially alter conclusions about the biogeochemical consequences of anthropogenic $\mathrm{N}$ deposition.

Interpretation of wood $\delta^{15} \mathrm{~N}$ trajectories depends on the relationship between soil $\mathrm{N}$ availability, foliar $\delta^{15} \mathrm{~N}$, and wood $\delta^{15} \mathrm{~N}$, providing another proxy for measuring $\mathrm{N}$ availability in soils through tree ring analysis (Craine et al., 2009). Briefly, stable $\mathrm{N}$ isotopes preserved in wood reflect multiple fractionating pathways within the $\mathrm{N}$ cycle. The main fractionating pathways are gaseous $\mathrm{N}$ losses to the atmosphere via microbially mediated processes. Conversion of ammonium to nitrate (nitrification), leaching of nitrate, mycorrhizal fungi providing depleted $\delta^{15} \mathrm{~N}$ to plants, and preferential uptake of ammonium by plants can ultimately alter the signal of plant $\delta^{15} \mathrm{~N}$. In most cases though, higher gaseous losses through denitrification and increased nitrification equates to higher $\mathrm{N}$ availability in the system and a more enriched $\delta^{15} \mathrm{~N}$ signal in the plant (Houlton et al., 2006). In forests, high $\delta^{15} \mathrm{~N}$ values are found in soils and leaves of ecosystems with high rates of nitrification (Pardo et al., 2006), high rates of denitrification (Houlton et al., 2006), partial nitrification followed by nitrate leaching (Pardo et al., 2002), and low reliance on mycorrhizal fungi for plant $\mathrm{N}$ uptake (Hobbie and Colpaert, 2003; Cuoto-Vazque and Gonzalez-Prieto, 2010). Stable $\mathrm{N}$ isotopes of wood from dated tree rings can produce high-resolution terrestrial records of past $\mathrm{N}$ cycling at specific locations that extend back in time several centuries.
Thus, wood $\delta^{15} \mathrm{~N}$ provides a useful proxy for analyzing spatiotemporal patterns of terrestrial $\mathrm{N}$ availability.

Old-growth forests dominated by red pine (Pinus resinosa) and white pine (Pinus strobus) once covered large areas of the north-central USA. Today, protected remnants of these forests provide valuable information regarding the role of natural disturbances like fire and windstorms in determining vegetation dynamics (Peet, 1984; Webb, 1989). Presettlement $P$. resinosa stands exhibit a variety of age structures (Fraver et al., 2012; Spurr, 1954), with maximum tree ages observed to be approximately 200 to 300 years (D'Amato et al., 2010; Silver et al., 2013). The disturbance regimes have been typically dominated by low-intensity surface fires that maintain an open understory, with occasional high-intensity stand-replacing fires (Clark, 1988, 1989). Severe stand-replacing wildfires can have a variety of effects on soil $\mathrm{N}$ cycling in northern conifer forests (Smithwick et al., 2005). During the past 100 years, $P$. resinosa forests have experienced substantial regeneration declines, expansion of hardwood species, and the development of dense undergrowth composed of pyrogenic species (Frissell, 1973). Increases in deer populations, along with severe drought episodes, have also hindered regeneration of pine species. As a result, neither $P$. resinosa nor $P$. strobus have been reproducing successfully since fire suppression began in the early 1920s (Ahlgren, 1975). One of the best-protected areas of old-growth $P$. resinosa is located at Itasca State Park in northern Minnesota (Minnesota DNR, 1998). Due to significant logging and intensification of agriculture in the region, Itasca is considered a relict of the vast northern coniferous forests. Additionally, given the well-documented time frame of park establishment (1891) and implementation of fire suppression $(\sim 1920$ s), $\mathrm{N}$ availability can be analyzed prior to and following human involvement, providing insight into how anthropogenic drivers can influence biogeochemical cycles in local terrestrial ecosystems.

Here, we analyze the spatiotemporal characteristics of $\mathrm{N}$ availability of $P$. resinosa within a mixed coniferous forest in Itasca State Park located in northwest Minnesota through use of nitrogen isotopes in tree rings. Our main objectives were to assess the long-term (century-scale) trajectory of $\mathrm{N}$ availability through isotopic analysis and additionally determine the influential drivers across space and time. We hypothesized that (1) nitrogen availability to the dominant tree species, P. resinosa, would be declining toward present at most sites within the watershed due to management-driven changes in fire regime in the early 20th century and that (2) there would be spatial heterogeneity within the temporal trend in the watershed, with individual $P$. resinosa trees exhibiting variable $\delta^{15} \mathrm{~N}$ trajectories based on location and geographic features. 


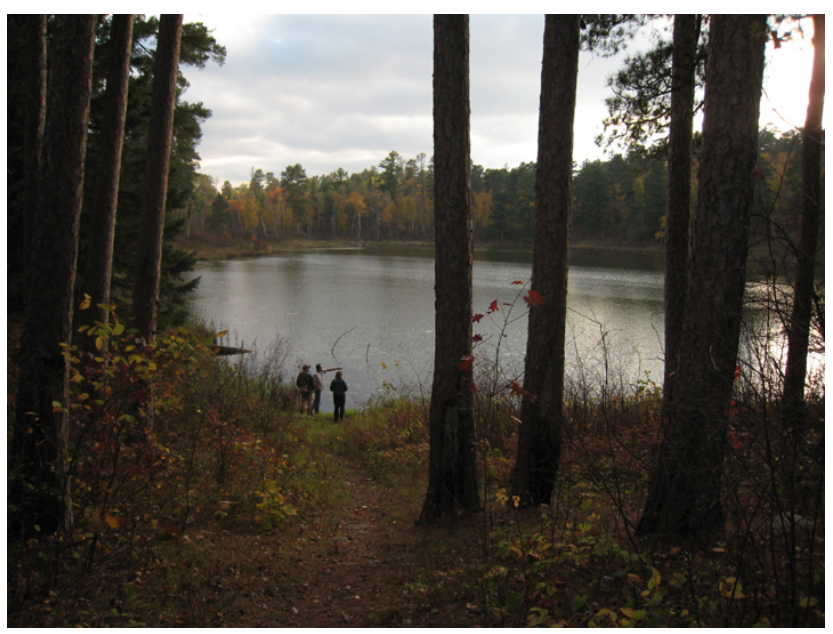

Figure 1. The Deming Lake watershed, looking west-southwest. $P$. resinosa and $P$. strobus are the most common species in this area, though understory vegetation includes smaller hardwoods, shrubs, and various grasses. Photo credit: Amy Myrbo.

\section{Methods}

\subsection{Study site}

Itasca State Park (ISP) in northern Minnesota is a large park (13 $229 \mathrm{ha}$ ) that lies on the Itasca moraine, deposited by the Laurentide Ice Sheet $13 \mathrm{kyr} \mathrm{BP}\left(47^{\circ} 14^{\prime} \mathrm{N}, 95^{\circ} 12^{\prime} \mathrm{W}\right)$. The upland soils of ISP are a mixture of sandy outwash and glacial till. Climate is typical of a northern temperate forest, with approximately $65 \mathrm{~cm}$ of annual precipitation and a mean annual temperature of $3{ }^{\circ} \mathrm{C}$ (National Climatic Data Center, 2000). The vegetation prior to Euro-American settlement in the region was a mixture of red pine ( $P$. resinosa), white pine (P. strobus), and jack pine (P. banksiana) forests and savannas, prairie openings, deciduous northern hardwood forests, and boreal bogs. Our study site, the Deming Lake watershed, lies within a mixed coniferous forest of Itasca State Park (Fig. 1). Fire was common in the region prior to human involvement, with varying fire return intervals anywhere from $\sim 8$ to 50 years over the last 750 years (Clark, 1990b). In recent years, several deciduous hardwood species have been increasing in abundance, including Acer saccharum (sugar maple), Betula papyrifera (paper birch), Corylus cornuta (beaked hazel), Populus tremuloides (aspen), P. grandidentata (big-toothed aspen), Quercus borealis (northern red oak), and Tilia americana (basswood). Corylus cornuta now dominates the understory (Kurmis and Sucoff, 1989). In the last 20 years, prescribed burns have been implemented in an attempt to stimulate regeneration of $P$. resinosa and reduce fuel loads (Santoro et al., 2001).

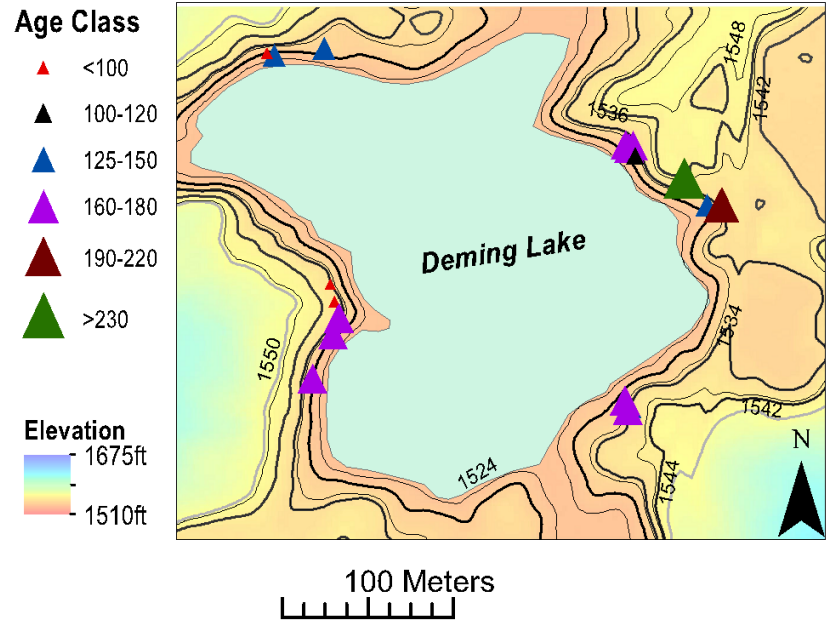

Figure 2. Contoured elevation map of Deming Lake (in feet) along with labeled contoured lines. The locations of the trees sampled are included, along with their respective age classes based on the size of the triangle. Note that some trees were sampled within close proximity to one another, so not all samples may be represented on the map.

\subsection{Field and laboratory methods}

Increment cores of $5.15 \mathrm{~mm}$ diameter were obtained at $1 \mathrm{~m}$ above the forest floor from 24 individual $P$. resinosa trees surrounding the Deming Lake watershed in March 2014 with a Haglöf borer. $P$. resinosa was the only species sampled because of its dominance, importance, and legacy to the area, as well as the need to use a single species to test our hypotheses. Samples were gathered from five stands comprising four to five trees with aspects of west, north, east, and south (Fig. 2). Trees were sampled at different elevations, slopes, and proximity to the shoreline to capture the spatial variation in $\delta^{15} \mathrm{~N}$ that may arise from small-scale topographic features or geographical position.

The cores were stored in plastic bags and dried at $65^{\circ} \mathrm{C}$. Each core was sanded then scanned at $1200 \mathrm{dpi}$. Ring widths of the cores were analyzed using both Cybis and the CDendro software (Saltsjöbaden, Sweden). The pith was reached on 11 out of the 24 samples; therefore the absolute age could not be determined for most trees but could nevertheless be dated based on cross-dating techniques and the last ring formation of 2013. The longest chronology contained 237 rings, while the shortest had 79 rings. Cores on average contained 145 rings (Table 1). Cores were weighed and divided into $10 \mathrm{mg}$ segments along ring boundaries that maximized temporal resolution while maintaining enough $\mathrm{N}$ in the sample for mass spectrometry. We did not apply any chemical pretreatments to the samples, as no universally accepted standardization method of sampling total $\mathrm{N}$ within wood has been developed. Pretreatment has been the focus of a number of studies and has been deemed unnecessary when trees 
are exposed to natural $\mathrm{N}$ inputs (i.e., unfertilized; Caceres et al., 2011). In both Caceres et al. (2011) and Doucet et al. (2011), the authors tested pretreatment methods on $\delta^{15} \mathrm{~N}$ for one species and found that while there may be effects of pretreatment on labile $\mathrm{N}$, pretreatment does not offset the overall trajectory. Since fertilizer has not been applied to this watershed or nearby, atmospheric $\mathrm{N}$ deposition is relatively low (average of $\sim 4-7 \mathrm{~kg} \mathrm{ha}^{-1}$ per year between 2011 and 2013), and the trajectory of $\mathrm{N}$ availability was the most important aspect of the research, pretreatment did not seem necessary (NADP, 2013). On average, wood samples comprised two or three annual rings, with a total of 1224 samples measured. Two cores were lost during measurement, and two were not measured for $\delta^{15} \mathrm{~N}$; therefore a total of 20 trees were used for subsequent analysis (Table 1).

The standardized ratio of ${ }^{15} \mathrm{~N}:{ }^{14} \mathrm{~N}$ relative to air $\left(\delta^{15} \mathrm{~N}\right)$ was determined for segments of wood at the University of Maryland Center for Environmental Science, Central Appalachian Stable Isotope Facility (CASIF) laboratory. The instrument is a Thermo Fisher Delta $\mathrm{V}+$ isotope ratio mass spectrometer fitted with sequential traps of $\mathrm{MgClO}_{4}, \mathrm{NaOH}$ on solid support (Carbosorb), and a cold trap in liquid $\mathrm{N}_{2}$.

\subsection{Statistical analyses}

In order to develop a spatiotemporal understanding of $\mathrm{N}$ cycling within the watershed, a number of statistical methods were employed. We set out to understand whether the effects of geography, geomorphology, and proximity to the shoreline of Deming Lake affected the overall mean values of $\delta^{15} \mathrm{~N}$ for each tree and the stands sampled. For instance, do trees closer to the lake exhibit a more depleted signal of $\delta^{15} \mathrm{~N}$ compared to those areas further away from the water body? To test for differences in mean, we utilized the Kruskal-Wallis and applied it to the averaged $\delta^{15} \mathrm{~N}$ values based on the standlevel mean, topography (based on slope percentage), elevation, and the trees location relative to the shoreline. For the latter test, distances from the shoreline were divided into three groups: those within $13.7 \mathrm{~m}$ of the shoreline (seven trees), between 13.7 and $16.8 \mathrm{~m}$ (seven trees), and greater than $16.8 \mathrm{~m}$ (six trees). Three groups were selected in an attempt to provide an adequate number and equal distribution of samples. For temporal analyses, we calculated standardized values by subtracting the mean $\delta^{15} \mathrm{~N}$ from each sample for each core, giving each a core a mean value of $0 \%$. This is essentially a $z$-score treatment, used in other isotopic analysis (McLauchlan et al., 2007). To test hypothesis 1 (evidence of trend), simple linear regression along with the rank-based, non-parametric Mann-Kendall trend test (MK test) were applied to each sample. Given its robustness for non-normally distributed data, the MK test is frequently applied to hydroclimatic time series data. The MK test determines the presence of a monotonic increasing or decreasing trend (given by the MK tau value), along with the magnitude of the slope calculated through the Sen's slope estimator. Trends determined by the test were deemed significantly different from zero if $p$ values were <0.05 (Mann, 1945; Sen, 1968).

After determining the trends and slopes of each core, a supplemental analysis sought to determine the date range of when the potential shift in mean occurred. We hypothesized that changes in $\mathrm{N}$ availability (particularly decreases) would be the result of a reduction in fire frequency through park management practices. Testing for a breakpoint allows us to assess whether a definitive change in $\mathrm{N}$ availability can be detected. Time-series-related studies, particularly in the climate and atmospheric sciences, often employ change-point analysis using a suite of tests. We applied four separate tests of change in the mean in order to improve bolster confidence that a change in mean does exist. Pettitt's test (Pettitt, 1979), Buishand's Bayesian test (Buishand, 1984), the standard normal homogeneity test (Alexandersson, 1986), and the cumulative deviation test (Rebstock, 2002) were applied to all samples. Relevant to our study, we used these tests to aid in our determination of whether a detectable human disturbance signature exists in the record. A great deal of research has been dedicated towards the study of detection procedures for identifying a potential change point in a data series. Many have argued that trends must be removed prior to detection of inhomogeneities, as trends (or autocorrelation) can create synthetic change points in a data set (Beaulieu et al., 2012). However, other studies have claimed that removing the trend component has the same adverse affect (Guerreiro et al., 2013). In our study we manipulated the data as little as possible (the exception being standardization) and applied no detrending methods prior to tests for shifts in mean. Regardless, using a diverse suite of change-in-mean tests allows for comparison of different tests on the same data sets. The use of multiple analyses allows a rigorous test of whether a detectable shift in $\delta^{15} \mathrm{~N}$ values exists.

\section{Results}

\subsection{Trends in $\delta^{15} \mathrm{~N}$}

Within the Deming Lake watershed, wood $\delta^{15} \mathrm{~N}$ has been significantly declining over the period of record as evident by the trajectories of individual trees. Of the 20 trees sampled, 17 demonstrated significantly declining trends toward present $(p<0.05)$ based on both simple linear regression and the MK test. The steepest declines tended to occur in trees located in stands 2 and 5 (northeast and south areas of the lake), although no clear cohesive spatial pattern could be detected (Table 2). Similarly, the length of the chronology had no apparent effect on the steepness of slope of the samples, as trees with similar ring counts had different rates of change.

To test our first hypothesis - that management practices have influenced $\mathrm{N}$ availability in $P$. resinosa in this watershed - we employed four statistical analyses to detect temporal breakpoints in the wood $\delta^{15} \mathrm{~N}$ time series. Of the 17 trees 
Table 1. List of the trees sampled, ring counts, the number of $\delta^{15} \mathrm{~N}$ samples obtained from that tree, elevation in meters, and distance from shore in meters.

\begin{tabular}{lrrrr}
\hline Tree & $\begin{array}{r}\text { Ring } \\
\text { counts }\end{array}$ & $\begin{array}{r}\# \delta^{15} \mathrm{~N} \\
\text { samples }\end{array}$ & $\begin{array}{r}\text { Elevation } \\
(\mathrm{m})\end{array}$ & $\begin{array}{r}\text { Distance from } \\
\text { shore }(\mathrm{m})\end{array}$ \\
\hline S1TC & 237 & 99 & 468 & 23.69 \\
S1TD & 122 & 44 & 469.5 & 20.63 \\
S1TE & 215 & 84 & 472.2 & 16.58 \\
S2TA & 175 & 98 & 474.5 & 14.28 \\
S2TB & 158 & 74 & 467.1 & 14.31 \\
S2TC & 162 & 55 & 465.2 & 12.57 \\
S2TD & 158 & 63 & 464.8 & 17.00 \\
S2TE & 79 & 50 & 467.7 & 13.20 \\
S3TA & 99 & 60 & 467 & 13.65 \\
S3TC & 118 & 49 & 469.5 & 10.29 \\
S3TD & 128 & 45 & 471.2 & 11.97 \\
S4TA & 95 & 35 & 470.4 & 9.35 \\
S4TB & 86 & 78 & 471 & 17.77 \\
S4TC & 171 & 64 & 468 & 16.82 \\
S4TD & 178 & 56 & 458 & 14.88 \\
S4TE & 159 & 51 & 466.1 & 9.30 \\
S5TA & 132 & 69 & 462.2 & 20.50 \\
S5TB & 110 & 68 & 462.2 & 20.50 \\
S5TC & 153 & 45 & 465.8 & 22.12 \\
\hline
\end{tabular}

Table 2. Slope based on simple linear regression $(m)$, Sen's slope and Kendall's tau value based on Mann-Kendall trend test for each tree. The Hamed and Rao method takes into account autocorrelation and adjusts the Sen's slope estimate. Tau values with * indicate $p<0.05$, ${ }^{* *} p<0.01$, and ${ }^{* * *} p<0.0001$; NS: not significant.

\begin{tabular}{lrrrr}
\hline Tree & $m$ & $p$ value & $\begin{array}{r}\text { Sen's slope (Hamed } \\
\text { and Rao method) }\end{array}$ & Kendall's tau \\
\hline S1TC & -0.0196 & $<0.0001$ & -0.029 & $-0.600^{* * *}$ \\
S1TD & 0.0101 & $<0.0001$ & 0.064 & $0.638^{* * *}$ \\
S1TE & -0.0067 & $<0.0001$ & -0.024 & $-0.355^{* * *}$ \\
S2TA & -0.0085 & $<0.0001$ & -0.022 & $-0.418^{* * *}$ \\
S2TB & -0.0163 & $<0.0001$ & -0.041 & $-0.657^{* * *}$ \\
S2TC & -0.0105 & $<0.0001$ & -0.045 & $-0.532^{* * *}$ \\
S2TD & -0.0150 & $<0.0001$ & -0.043 & $-0.518^{* * *}$ \\
S2TE & -0.0101 & $<0.0001$ & -0.080 & $-0.532^{* * *}$ \\
S3TA & 0.0061 & $<0.05$ & 0.017 & $0.214^{*}$ \\
S3TC & -0.0078 & $<0.0001$ & -0.037 & $-0.461^{* * *}$ \\
S3TD & -0.0077 & $<0.0001$ & -0.051 & $-0.554^{* * *}$ \\
S4TA & -0.0003 & $\mathrm{NS}$ & -0.003 & $-0.025 \mathrm{NS}$ \\
S4TB & -0.0170 & $<0.0001$ & -0.042 & $-0.576^{* * *}$ \\
S4TC & -0.0145 & $<0.0001$ & -0.038 & $-0.587^{* * *}$ \\
S4TD & -0.0014 & $<0.05$ & -0.013 & $-0.176^{*}$ \\
S4TE & -0.0075 & $<0.0001$ & -0.039 & $-0.442^{* * *}$ \\
S5TA & -0.0095 & $<0.0001$ & -0.050 & $-0.546^{* * *}$ \\
S5TB & -0.0156 & $<0.0001$ & -0.040 & $-0.606^{* * *}$ \\
S5TC & -0.0128 & $<0.0001$ & -0.044 & $-0.674^{* * *}$ \\
S5TD & -0.0094 & $<0.001$ & -0.058 & $-0.371^{* *}$ \\
\hline
\end{tabular}

with negative trajectories, a significant breakpoint $(p<0.05)$ could be detected based on each test in all 17 cases. However, the timing varied in some trees. In the 13 out of the 17 trees, a similar breakpoint (within one data point) was evident for the four tests (Table 3). In the case of S2TA, where significant breakpoints were evident but the timing differed, 
Table 3. Estimation of the timing of when a significant change in mean of $\delta^{15} \mathrm{~N}$ could be detected for each tree utilizing the four different breakpoint tests described in the methods sections. The asterisks indicate that the test detected a significant breakpoint $<0.05$ for a given year. Note that the timing of when a significant change was detected may differ based on the statistical method used, and note also that the trees with positive trends were not included in these tests.

\begin{tabular}{lrrrr}
\hline Tree & $\begin{array}{r}\text { Buishand's } \\
\text { test }\end{array}$ & $\begin{array}{r}\text { CUSUM } \\
\text { test }\end{array}$ & $\begin{array}{r}\text { Pettitt's } \\
\text { test }\end{array}$ & SNTH \\
\hline S1TC & $1941^{*}$ & $1942^{*}$ & $1941^{*}$ & $1942^{*}$ \\
S1TE & $1925^{*}$ & $1925^{*}$ & $1925^{*}$ & $1925^{*}$ \\
S2TA & $1928^{*}$ & $1942^{*}$ & $1927^{*}$ & $1949^{*}$ \\
S2TB & $1930^{*}$ & $1930^{*}$ & $1930^{*}$ & $1930^{*}$ \\
S2TC & $1935^{*}$ & $1935^{*}$ & $1935^{*}$ & $1935^{*}$ \\
S2TD & $1958^{*}$ & $1956^{*}$ & $1956^{*}$ & $1958^{*}$ \\
S2TE & $1973^{*}$ & $1975^{*}$ & $1973^{*}$ & $1983^{*}$ \\
S3TC & $1942^{*}$ & $1942^{*}$ & $1942^{*}$ & $1942^{*}$ \\
S3TD & $1917^{*}$ & $1917^{*}$ & $1920^{*}$ & $1917^{*}$ \\
S4TA & 1980 & 1996 & 1980 & 2008 \\
S4TB & $1947^{*}$ & $1947^{*}$ & $1926^{*}$ & $1947^{*}$ \\
S4TC & $1943^{*}$ & $1943^{*}$ & $1933^{*}$ & $1943^{*}$ \\
S4TD & $1941^{*}$ & $1941^{*}$ & $1941^{*}$ & $1941^{*}$ \\
S4TE & $1968^{*}$ & $1968^{*}$ & $1968^{*}$ & $1968^{*}$ \\
S5TA & $1941^{*}$ & $1941^{*}$ & $1943^{*}$ & $1939^{*}$ \\
S5TB & $1924^{*}$ & $1923^{*}$ & $1923^{*}$ & $1923^{*}$ \\
S5TC & $1923^{*}$ & $1923^{*}$ & $1929^{*}$ & $1923^{*}$ \\
S5TD & $1927^{*}$ & $1927^{*}$ & $1927^{*}$ & $1927^{*}$ \\
\hline
\end{tabular}

extreme values occurring within a 20 -year period more than likely distorted the signal creating the differences, as removal of the outliers in the period resulted in the temporal agreement of a breakpoint.

Breakpoint tests were then applied to larger-scale watershed-level wood $\delta^{15} \mathrm{~N}$ based on averaging the time series for all trees. Using this chronology, a significant breakpoint of 1927 CE was detected (Fig. 3). A piecewise regression was also applied to the time series to show the varying trajectories prior to and after $1927 \mathrm{CE}$. A slight positive trend exists (not significant) prior to $1927 \mathrm{CE}$, and the major decline in wood $\delta^{15} \mathrm{~N}$ did not begin until the 1930s.

Both parts of our first hypothesis are supported by these results, if tests for breakpoints are good estimates of when shifts in mean occurred. Fire suppression began in the 1920s, and in 13 cases a change in mean could be detected within the period of 1920 to 1947 . It is important to note that it would take time for the potential mechanisms affecting levels of $\mathrm{N}$ availability to change after a change in disturbance regime. As a result, there would be a lagged effect from the time of altered disturbance regime to when significant declining $\mathrm{N}$ availability would be evident in the wood $\delta^{15} \mathrm{~N}$ record of already established species such as $P$. resinosa. Without using homogeneity tests to assess whether a change point exists, trees with sufficient data records prior to $1925 \mathrm{CE}$ (> 15

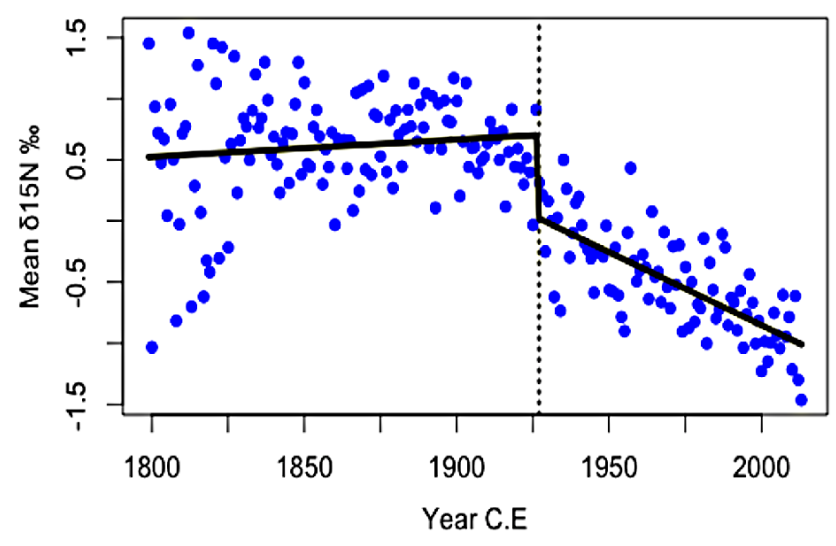

Figure 3. Piecewise regression line fit to the standardized $\delta^{15} \mathrm{~N}$ for the entire study site. For purposes of larger sample size, data for the period 1800-2013 were selected. The dashed line represents the significant change point of 1927 determined by changepoint tests. Sen's slope prior to the determined 1927 breakpoint based on Mann-Kendall trend test is slightly positive albeit not significant $(p=0.972)$. The period of $1927-2013$ has a significant $(p<0.00001)$ Sen's slope of -0.012 .

samples before 1925) were divided into two periods: $\delta^{15} \mathrm{~N}$ prior to 1925 , and $\delta^{15} \mathrm{~N}$ after 1925 . Tests for trend were applied to the two time series to see whether slopes significantly differed. Indeed, in the analysis of the 15 trees used, 10 exhibited no significant trend ( $p>0.5), 3$ trees had significantly increasing trends, and 2 had significantly downward trends. Tests of the data following 1925, however, reveal similar trends to those discussed initially, with 16 trees having significantly negative trends, 1 tree with a negative trend, 2 trees with significantly upward trends, and 1 with no significant trend. Therefore, even without removing any trends, it is clear that these trees exhibit breakpoints in wood $\delta^{15} \mathrm{~N}$ trajectories, with a shift beginning in the 1920s.

\subsection{Spatial characteristics of $\delta^{15} \mathrm{~N}$}

To test our second hypothesis, we examined the spatial patterns of wood ${ }^{15} \mathrm{~N}$ values at several levels of spatial organization. First, for individual trees, raw $\delta^{15} \mathrm{~N}$ values exhibited a high degree of heterogeneity and spatial variation, with maximum $\delta^{15} \mathrm{~N}$ values for an individual tree ranging from $3.46 \%$ (S1TC) to $-0.06 \%$ (S5TD) and minimum values ranging from -1.76 (S4TE) to $-4.38 \%$ (S2TC; Fig. 4a). The average standard deviation for all trees sampled was $1.22 \%$ o. Tests among all trees revealed significantly different mean $\delta^{15} \mathrm{~N}(p<0.00001)$, not surprising given the multitude of environmental factors that alter levels of $\mathrm{N}$ availability. With significantly different variances in the data set detected, the Games-Howell test was used in the post hoc tests. Means of $\delta^{15} \mathrm{~N}$ for each tree significantly differed on average from 9 (8.7) other trees. Outliers in the post hoc tests included tree S1TD, located in stand 1 on the east end of the lake, and 


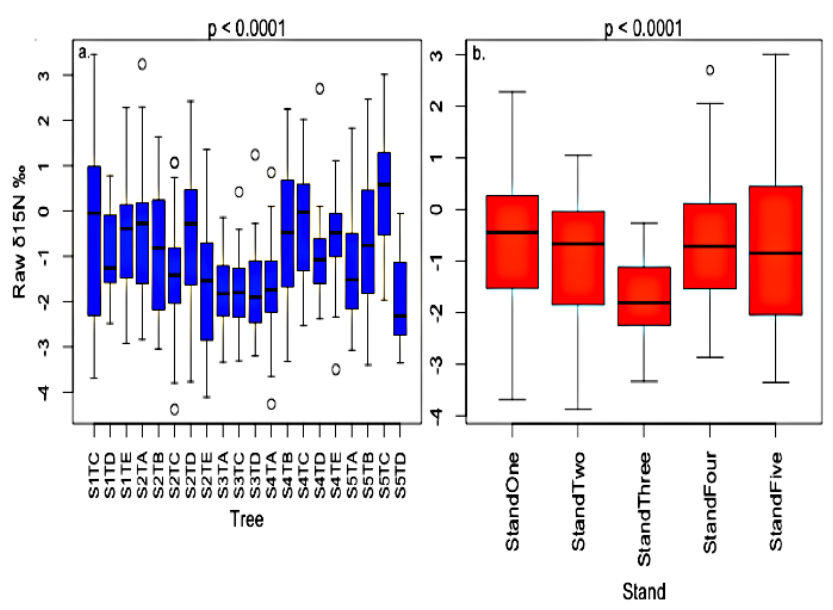

Figure 4. Box plots showing differences in means between trees (a) and stands (b). (a) Box plot of $\delta^{15} \mathrm{~N}$ for each tree. $\mathrm{S}$ refers to the stand (i.e., S1: stand 1), and T refers to tree (T1: tree 1). (b) Same as Fig. $4 \mathrm{a}$ but for the five stands analyzed. The box plots are based on the averages from each stand. Data averaged over the time series.

S5TC located in stand 5 on the south end of the lake. The former significantly differed from only two trees, while the latter significantly differed from 17 trees.

Second, spatial patterns were also analyzed at the stand level. An initial ANOVA test based on group means of the five stands sampled once again revealed significant $(p<0.00001)$ differences among stands, although post hoc analysis indicated that only stand 3 , consisting of those trees on the north end of the lake, significantly differed from the other four groups. The trees within this stand by far had the lowest $\delta^{15} \mathrm{~N}$ average (by over 1\%o) and the least amount of variation (Fig. 4b).

One unexpected result from the proximal tests was a change in average wood $\delta^{15} \mathrm{~N}$ value with distance from the shoreline. Values of wood $\delta^{15} \mathrm{~N}$ for trees closest to Deming Lake averaged $-1.54 \%$, followed by $-0.77 \%$ ofor the second closest group, and finally $-0.64 \%$ o for the group furthest from the lake. Inversely, higher variation in $\delta^{15} \mathrm{~N}$ was present in those trees furthest away from Deming Lake (1.47 standard deviations), followed by 1.26 for the intermediate distance group and 1.10 for the trees closest to the lake. The decline in $\delta^{15} \mathrm{~N}$ from trees sampled further out to trees close to the shoreline could be the result of trees incorporating a more enriched signal of $\delta^{15} \mathrm{~N}$ in higher elevations and through leaching processes, a more depleted signal is left for trees closest to the shoreline. Since the catchment is not steeply sloped and the parent material is derived from glacial till, soil properties would not appear to be a viable explanation for the watershed-scale differences. Although topographical differences could alter the fire frequency, recent prescribed burns of low-intensity similar to those that occurred naturally burned to the edge of the water. Given the lake is fed by groundwater and has remained relatively stable during the Holocene (McLauchlan et al., 2013b), changes in lake levels would also not be a significant influence on $\mathrm{N}$ availability. A sampling technique (i.e., cross-sectional or pointquarter sampling methods) geared towards assessing the spatial changes in $\delta^{15} \mathrm{~N}$ would better address the explanations described here.

In terms of the variability in trajectories based on location and geographic features, the tests for breakpoints struggle to agree on breakpoint timing for the two groups closest to Deming Lake. Albeit significant, the timing of the breakpoints vary anywhere from 1927 to 1973 . Conversely, for the trees furthest from the lake all tests agree on a significant 1924 breakpoint $(p<0.0001)$. The inability to agree on a similar breakpoint value more than likely results from averaging the $\delta^{15} \mathrm{~N}$ values for trees in a similar group, creating incredible variability and making it difficult to assess whether a change in mean exists. Indeed, using a 5-year smoothing filter results in much better agreement among breakpoint tests for the two groups, with values in the 13.7$16.7 \mathrm{~m}$ group varying from 1926 to 1941 , while the closest group of trees having a breakpoint value of 1926 based on all tests $(p<0.0001)$. Relative to the group trajectories, based on simple linear regression only the slope of the closest group of trees significantly differed from the others $(p<0.0001)$. The steepest decline was also present in this group. Conversely, when assessing the slopes after 1925, the most negative slopes occurred in the group of trees within 13.7-16.8 m, followed by the group $<13.7 \mathrm{~m}$ to the lake. Only the group furthest away significantly differed from the other two in terms of their trajectories following 1925. The two trees with increasing trajectories toward present appear to have no obvious landscape characteristics that explain those patterns. With respect to the trajectory based on the incline of the surface, once again three groups were created based on the criteria locations with $>19 \%$ change in slope, between 14 and $19 \%$ slope, and finally $<14 \%$. Trees with the highest percentage change in slope had significantly different slope values than the other two groups. While a similar breakpoint could be agreed upon with the two latter groups listed above (1926 and 1927 at $p<0.0001$ ), a breakpoint could not be determined for trees with the highest slopes. Once again this may result from a decreased sample size within the group. The largest decline also occurred within this group, followed by trees residing on terrain with $14-19 \%$ slope. In addition to there being significant spatial differences in wood $\delta^{15} \mathrm{~N}$ demonstrated in this study within a spatial extent of $676 \mathrm{~m}^{2}$, our second hypothesis, about spatial differences in wood $\delta^{15} \mathrm{~N}$ trajectories, appears to be supported as well despite the overall agreement of declining $\delta^{15} \mathrm{~N}$.

\subsection{Terrestrial and lacustrine records}

Given the strong signal of declines in terrestrial $\delta^{15} \mathrm{~N}$, we compared the wood $\delta^{15} \mathrm{~N}$ record to a previously published sediment record from Deming Lake for the portion of tem- 


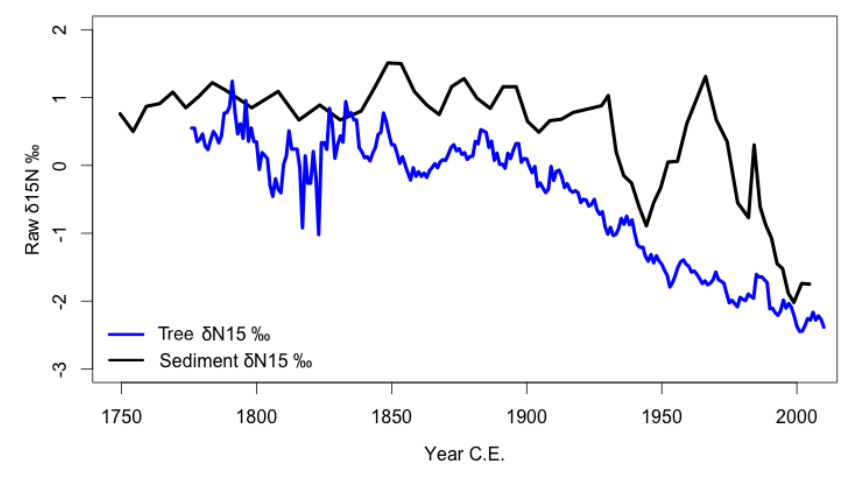

Figure 5. Comparison of sediment ${ }^{15} \mathrm{~N}$ record with a 5-year smoothed raw wood ${ }^{15} \mathrm{~N}$ record. The blue line indicates the wood $15 \mathrm{~N}$ record (1776-2013), and the black line indicates the sediment ${ }^{15} \mathrm{~N}$ record (1749.5-2004.7).

poral overlap - approximately the last 250 years (McLauchlan et al., 2013b). There is remarkable coherence between these two records. The most noticeable characteristic of both time series is the noticeably similar steep decline of $\delta^{15} \mathrm{~N}$ beginning in the 20th century. The same breakpoint tests used on the wood $\delta^{15} \mathrm{~N}$ were applied to sedimentary $\delta^{15} \mathrm{~N}$ using the period of data from 1750 to $2004 \mathrm{CE}$ In three of the four tests, a change point of $1930 \mathrm{CE}$ was detected (all significant at $\mathrm{p}<0.01)$. The values of terrestrial $\delta^{15} \mathrm{~N}$, on average, are smaller (more negative) than values of sedimentary $\delta^{15} \mathrm{~N}$. While it would be ideal to test a larger portion of the sedimentary time series to accurately identify the change in mean, the two data sets share a remarkable degree of similarity during the past $\sim 250$ years (Fig. 5).

\section{Discussion}

Available nitrogen has clearly been declining over time in $P$. resinosa within the Deming Lake watershed. A robust set of breakpoint analyses identify the early 1920s as the time when a synchronous decline in wood $\delta^{15} \mathrm{~N}$ values began. Declines in wood $\delta^{15} \mathrm{~N}$ values toward present have been described in a number of studies and attributed to a variety of causes, described below (Gerhart and McLauchlan, 2014). Because of the synchrony of the breakpoint, the timing, and the direction of change (decline toward present), we believe the primary reason for the substantial decline in $\delta^{15} \mathrm{~N}$ over the past century has been management practices within the state park, namely fire suppression that began in the late 1910s. Disturbance regimes, both human and natural, can have profound impacts on nutrient cycling resulting from complex spatial and temporal patterns that affect primary productivity and biomass accumulation (Clark, 1988). In the case of fire, disturbance can influence $\mathrm{N}$ availability both on short and longterm scales. In the short term, fire impacts organic-matter pools (Wang et al., 2012), while on longer timescales fire can alter species composition, subsequently influencing total carbon and N pools (Clark, 1990a; Nave et al., 2011). Fire suppression of the type of low-intensity ground fires common to $P$. resinosa forests allows for competing understory species to increase in abundance, both increasing plant demand for $\mathrm{N}$ and increasing annual litter input to the forest floor, thereby lowering the availability of nitrogen for tree species dependent on a semi-regular fire regime (Brisson et al., 1988; Tappeiner and Alm, 1975). Indeed, fire suppression of ponderosa pine forests in the western USA has been demonstrated to reduce $\mathrm{N}$ availability up to 130 years after the onset of fire suppression through reduced net $\mathrm{N}$ mineralization and nitrification potential (MacKenzie et al., 2006). We suggest that these changes in nutrient status may be contributing to the regeneration problems previously documented for $P$. resinosa in the northern USA. After a burn, $P$. resinosa invades burned regions by seeding from other trees nearby which were unaffected by the fire. With a reduction in generation, competing species are allowed to propagate. It has been suggested that the old-growth pine forests of not only Itasca but much of the northern USA may eventually succeed to northern hardwoods, as regeneration attempts of pine species in the region have failed with fire suppression (Zenner and Peck, 2009).

Altered biogeochemistry would explain the sharp declines in wood $\delta^{15} \mathrm{~N}$ in many of the trees following the implementation of a no-burn policy in the 1920s. Significant declines in wood $\delta^{15} \mathrm{~N}$ of many of the trees sampled here did not begin until the early-mid-20th century. It is logical to believe that, if this practice did in fact alter nutrient cycling at Deming Lake, it would have been a lagged effect. However, it is worth mentioning that some trees decline immediately following fire suppression, while with others the sharp decline does not begin for up to 15 to 20 years later. While we do believe the evidence highly suggests a large-scale disturbance altered the biogeochemistry of the watershed, there are various standlevel and micro-level spatial effects that may alter the timing of disturbance response. Further, the last recorded fire at Deming Lake occurred in 1917 and was not a watershedscale fire; therefore certain areas affected by the burn may have been more resistant to understory growth compared to unaffected areas in the watershed (Clark, 1990a). Studies have documented the effects on $\mathrm{N}$ availability following human disturbance. Bukata and Kyser (2007) analyzed the effects of tree-clearing and land-use change on Quercus alba (white oak) and Quercus rubra (red oak) in forest stands in Ontario, Canada. Their results showed that trees on the outer edges of the stand showed an almost immediate marked increase in $\delta^{15} \mathrm{~N}$ compared to those in the center, coinciding with the tree-clearing event and land-use change. This study emphasizes the role of shifting ecosystem composition on $\delta^{15} \mathrm{~N}$ values resulting from human activity.

There are several alternative explanations for declining wood $\delta^{15} \mathrm{~N}$ values that have been published in the literature (see Gerhart and McLauchlan, 2014, for a summary). Similar patterns of decline in wood $\delta^{15} \mathrm{~N}$ observed elsewhere 
have been attributed to increases in atmospheric $\mathrm{N}$ deposition. This might be plausible if $\delta^{15} \mathrm{~N}$ in $\mathrm{NO}_{x}$ were much lower compared to soil $\delta^{15} \mathrm{~N}$, and if the quantity of deposited $\mathrm{N}$ were sufficient to alter either the isotopic signature or cycling of soil N. Poulson et al. (1995) first hypothesized that a decreasing trend over time of $\delta^{15} \mathrm{~N}$ in rings of $T$. canadensis (eastern hemlock) stemmed from increased deposition of depleted ${ }^{15} \mathrm{~N}$ compounds due to an increase in $\mathrm{NO}_{x}$ and $\mathrm{NH}_{3}$ emissions in the late 20th century. Although the area lies on the boundary between low $\mathrm{N}$ deposition levels and higher levels in the southern Minnesota and Iowa, the lack of agriculture and large-scale industry in northwest Minnesota as well as the declines predating widespread human manipulation of the global $\mathrm{N}$ cycle, it is difficult to posit this as a viable explanation for the patterns evident at this site.

Declining $\delta^{15} \mathrm{~N}$ may also be attributed to a physiological process in plants or a time course of ecosystem processes in soils. As a tree ages, uptake of $\mathrm{N}$ switches from an open cycle to a closed cycle resulting from decreasing nutrient losses and increasing stand age (Jussy et al., 2000). Perhaps the sources supplying $\mathrm{N}$ to the tree change with age as well, with sources in the most recent growth years containing more $\mathrm{N}$ depleted in ${ }^{15} \mathrm{~N}$ than those which supplied the tree in the early stages of its life (Hobbie and Hobbie, 2006). More than likely some physiological factors influence $\mathrm{N}$ cycling within $P$. resinosa and could perhaps be genus- or species-dependent, but physiologically related explanations fail to account for the rapid step change in $\delta^{15} \mathrm{~N}$ seen in a majority of the trees beginning in the 1920s. With age classes exhibiting declines ranging anywhere from $\sim 100$ to $\sim 240$ years, coupled with the high degree of spatial heterogeneity in terms of $\delta^{15} \mathrm{~N}$, an external process is the most likely hypothesis for driving declines in $\mathrm{N}$ availability.

Despite the overall synchronous trajectory among trees, certain geographical differences resulted in different spatial signatures of $\delta^{15} \mathrm{~N}$. In old-growth $P$. resinosa forests, Clark (1990a) identified topographic position as an important driver of $\mathrm{N}$ mineralization rates, with spatial variation in soil moisture correlated with microbial activity. In our study, trees on the north side of the lake in a more open stand structure had the lowest average levels of wood $\delta^{15} \mathrm{~N}$. Scattered and large $P$. resinosa dominated this area (highest average diameter at breast height (DBH) among stands) with relatively few tree/shrub species in the understory present. Average levels of $\delta^{15} \mathrm{~N}$ also differed based on proximity to the lake, with samples furthest away containing the highest averages and variances compared to those closer to water body. It would be pertinent in future studies to further investigate the role landscape position plays in $\delta^{15} \mathrm{~N}$ signatures of both soil and plants.

Additional questions arise as the result of the striking similarities between the $\delta^{15} \mathrm{~N}$ values of the sediment record analyzed in McLauchlan et al. (2013b) and our results. The marked decline in $\delta^{15} \mathrm{~N}$ in the latter part of the sediment record has been attributed to internally driven processes occurring within the lake, particularly the development of anaerobic conditions in the deeper areas of the lake. Over the past 500 years, $\delta^{15} \mathrm{~N}$ in the sediment record has been declining markedly, although a somewhat stable period is present from 1600 to 1900 followed by a drastic decline in the 20th century. The identical temporal pattern of nearby wood $\delta^{15} \mathrm{~N}$ suggests either different mechanisms driving the same pattern in the two records or a need to reassess the contribution of terrestrial inputs to the sedimentary record. This result, of dendrochronological and sedimentary $\delta^{15} \mathrm{~N}$ records from the same small catchment showing strong agreement in their respective trajectories, has also been seen at an oligotrophic lake in New Hampshire (McLauchlan et al., 2007) and a high-elevation lake in the western USA (Wolfe et al., 2013). Each of these sites has a different land-use history and a different $\mathrm{N}$ cycle, but each has demonstrated a decline in $\delta^{15} \mathrm{~N}$ in the past century. The ubiquity of 20th century declines in $\delta^{15} \mathrm{~N}$ values in various ecosystem pools, and possible regional or global-scale drivers, is an area deserving much further investigation.

Overall, the results of our study analyzing the spatiotemporal characteristics of $\delta^{15} \mathrm{~N}$ in a pine-dominated forest of northwest Minnesota demonstrate declining $\mathrm{N}$ availability for the past 80 years, for which we hypothesize that the decline coincides with the onset of fire suppression by park managers of Itasca State Park beginning in the early 20th century. Three different proxy data sets derived from the watershed exhibit a decline (Clark, 1990b; charcoal record, $\delta^{15} \mathrm{~N}$ record in wood, $\delta^{15} \mathrm{~N}$ in the sediment) that coincides with a major ecosystem-scale disturbance. This study is the longest wood $\delta^{15} \mathrm{~N}$ chronology published, with $\delta^{15} \mathrm{~N}$ values from wood dated to 1776 CE (237 years ago). However, it cannot be said with full certainty that the declines are the result of a single mechanism. More complicated and alternative hypotheses cannot be ruled out without incorporation of additional data (i.e., precise fire history from the watershed calibrated with $\delta^{15} \mathrm{~N}$ data, or additional data sets about the temporal trajectory of $\delta^{15} \mathrm{~N}$ in pine species). Therefore, until additional work is conducted on the effects of altered fire regimes on nitrogen availability, the data set presented here should be treated as strong evidence but not a direct test of our main hypothesis. Although selection of a single tree species $(P$. resinosa) provided an intriguing spatial and temporal picture of $\delta^{15} \mathrm{~N}$, it would be useful to sample additional old-growth forests, and wood $\delta^{15} \mathrm{~N}$ of some of the understory species that became abundant with fire suppression to obtain a more complete answer about the mechanism of these declines in $\delta^{15} \mathrm{~N}$. Other elemental cycles (i.e., carbon and phosphorus) and their association with changes in $\mathrm{N}$ availability would also provide a more coherent explanation of why these drastic changes have occurred and the role of changing environmental conditions in altering $\mathrm{N}$ cycling on local spatial scales. 
Acknowledgements. This work was supported through NSF grant BCS-0955225 awarded to K.K. McLauchlan. We thank Jon Ross at Itasca State Park for logistical assistance, and the Minnesota Department of Natural Resources for a scientific research permit. Courtney Howard provided field assistance, and Robin Paulman conducted the isotopic analyses at CASIF. P. R. Leavitt produced sediment data about Deming Lake, and we thank him, Laci Gerhart Barley, and Kyleen Kelly for helpful discussions.

Edited by: S. Zaehle

\section{References}

Ahlgren, C. E.: Regeneration of red pine and white pine following wildfire and logging in northeastern Minnesota, J. Forest., 74, 135-140, doi:10.3375/043.029.0208, 1975.

Alexandersson, H.: A homogeneity test applied to precipitation data, J. Climatol., 6, 661-675, doi:10.1002/joc.3370060607, 1986.

Beaulieu, C., Chen, J., and Sarmiento, J.L .: Change-point analysis as a tool to detect abrupt climate variations, Philos. T. R. Soc. A., 370, 1228-1249, doi:10.1175/JCLI4291.1, 2012.

Beghin, R., Cherubini, P., Battipaglia, G., Siegwolf, R., Saurer, M., and Bovio, G.: Tree-ring growth and stable isotopes $\left(\delta^{13} \mathrm{C}\right.$ and $\delta^{15} \mathrm{~N}$ ) detect effects of wildfires on tree physiological processes in Pinus sylvestris L, Trees, 25, 627-636, doi:10.1007/s00468011-0539-9, 2011.

Bernal, S., Hedin, L. O., Likens, G. E., Gerber, S., and Buso, D. C.: Complex response of the forest nitrogen cycle to climate change, P. Natl. Acad. Sci. USA, 109, 3406-3411, doi:10.1073/pnas.1121448109, 2012.

Brisson, J., Bergeron, Y., and Bouchard, A.: Secondary succession on mesic sites in the Upper St. Lawrence Region, Quebec, Canada, Can. J. Bot., 6, 1192-1203, doi:10.1139/b88-170, 1988.

Buishand, T. A.: Tests for detecting a shift in the mean of a hydrological time series, J. Hydrol., 73, 51-69, doi:10.1016/00221694(84)90032-5, 1984.

Bukata, A. R., and Kyster, T. K.: Carbon and nitrogen isotope variations in tree-rings as records of perturbations in regional carbon and nitrogen cycles, Env. Sci. Tech., 41, 1331-1338, doi:10.1021/es061414g, 2007.

Cacerces, M. K., Mizota, C., Yamanaka, T., and Nobori, Y.: Effects of pre-treatment on the nitrogen isotope composition of Japanese black pine (Pinus thunbergii) tree-rings as affected by high N input, Rapid Commun. Mass Spectrom, 21, 3298-3302, doi:10.1002/rcm.5227, 2011.

Clark, J. S.: Effect of climate change on fire regimes in northwestern Minnesota, Nature 334, 233-235, doi:10.1038/334233a0, 1988.

Clark, J. S.: Effects of long-term water balances on fire regime, north-western Minnesota, J. Ecol, 77, 989-1004, 1989.

Clark, J. S.: Landscape interactions among nitrogen mineralization, species composition, and long-term fire frequency, Biogeochemistry, 11, 1-22, doi:10.1007/BF00000849, 1990a.

Clark, J. S.: Fire and climate change during the last $750 \mathrm{yr}$ in northwestern Minnesota, Ecol. Monogr., 60, 135-159, doi:10.2307/1943042, 1990b.

Craine, J. M., Elmore, A. J., Aidar, P., Bustamante, M., Dawson, T. E., Hobbie, E. A., Ansgar, K., Mack, M. C., McLauchlan, K.
K., Michelsen, A., Nardoto, G. B., Pardo, L. H., Peñuelas, J., Reich, P. B., Schuur, E. A. G., Stock, W. D., Templer, P. H., Virginia, R. A., Welker, J. M., and Wright, J. A: Global patterns of foliar nitrogen isotopes and their relationships with climate, mycorrhizal fungi, foliar nutrient concentrations, and nitrogen availability, New Phytol., 183, 980-992, doi:10.1111/j.14698137.2009.02917.x, 2009.

Cuoto-Vázquez, A. and González-Prieto, S. J.: Effects of climate, tree age, dominance and growth on $\delta^{15} \mathrm{~N}$ in young pinewoods, Trees, 24, 507-514, doi:10.1007/s00468-010-0420-2, 2010.

D'Amato, A. W., Palik, B. J., and Kern, C. C.: Growth, yield, and structure of extended rotation Pinus resinosa stands in Minnesota, USA, Can. J. For. Res., 40, 1000-1010, doi:10.1139/X10-041, 2010.

Doucet, A., Savard, M. M., Bégin, C., and Smirnoff, A.: Is pre-treatment essential for tree-ring nitrogen concentration and isotope analysis?, Rapid Commun. Mass Spec., 25, 469-475, doi:10.1002/rcm.4876, 2011.

Fraver, S., Palik, B. J., and Brian, J.: Stand cohort structures of old-growth Pinus resinosa- dominated forests of northern Minnesota, USA, J. Veg. Sci., 23, 249-259, doi:10.1111/j.16541103.2011.01348.x, 2012.

Frissell, J.: The importance of fire as a natural ecological factor in Itasca State Park, Minnesota, Quaternary Res., 3, 397-407, doi:10.1016/0033-5894(73)90005-7, 1973.

Galloway, J. N., Dentenner, F. J., Capone, D. G., Boyer, E. W., Howarth, R. W., Seitzinger, S. P., Asner, G. P., Cleveland, C. C., Green, P. A., Holland, E. A., Karl, D. M., Michaels, A. F., Porter, J. H., Townsend, A. R., and Vöosmarty, C. J.: Nitrogen cycles: past, present, and future, Biogeochemistry, 70, 153-226, doi:10.1007/s10533-004-0370-0, 2004.

Gerhart, L. and McLauchlan, K. K.: Reconstructing terrestrial nutrient cycling using stable nitrogen isotopes in wood, Biogeochemistry, 120, 1-21, doi:10.1007/s10533-014-9988-8, 2014.

Guerreiro, S., Kilsby, C. G., and Serinaldi, F.: Analysis of time variation of rainfall in transnational basins in Iberia: abrupt changes or tends?, Int. J. Climatol., 34, 114-133, doi:10.1002/joc.3669, 2013.

Hietz, P., Dünish, O., and Wanek, W.: Long-term trends in nitrogen isotope composition and nitrogen concentration in Brazilian rainforest trees suggest changes in nitrogen cycle, Env. Sci. Tech., 44, 1191-1196, doi:10.1021/es901383g, 2010.

Hietz, P., Turner, B. L., Wanek, W., and Richter, A., Nock, C. A., and Wright, S. J.: Long-term change in nitrogen cycle of tropical forests, Science, 334, 664-666, doi:10.1126/science.1211979, 2011.

Hobbie, J. E. and Colpaert, J. V.: Nitrogen availability and colonization by mycorrhizal fungi correlate with nitrogen isotope patterns in plants, New Phytol., 157, 115-126, doi:10.1046/j.14698137.2003.00657.x, 2003.

Hobbie, J. E. and Hobbie, E. A.: ${ }^{15} \mathrm{~N}$ in symbiotic fungi and plants estimates nitrogen and carbon flux rates in arctic tundra, Ecology, 87, 816-822, doi:10.1890/00129658(2006)87[816:NISFAP]2.0.CO;2, 2006.

Houlton, B. Z., Sigman, D. M., and Hedin, L. O.: Isotopic evidence for large gaseous nitrogen losses from tropical rainforests, P. Natl. Acad. Sci. USA, 103, 8745-8750, doi:10.1073/pnas.0510185103, 2006. 
Houlton, B. Z., Boyer, E., Finzi, Adrien, Galloway, J., Leach, A., Liptzin, D., Melillo, J., Rosenstock, T. S., Sobota, and D., Townsend, A. R.: Intentional versus unintentional nitrogen use in the United States: trends, efficiency and implications, Biogeochemistry, 114, 11-23, doi:10.1007/s10533-012-9801-5, 2013.

Jussy, J. H., Colin-Belgrand, M., and Ranger, J.: Production and root uptake of mineral nitrogen in a chronosequence of Douglasfir (Pseudotsuga menziesii) in the Beaujoalis Mountains, Forest Ecol. Manage., 128, 197-209, doi:10.1007/s10533-012-9801-5, 2000.

Kareiva, P., Watts, S., McDonald, R., and Boucher, T.: Domesticated nature: shaping landscapes and ecosystems for human welfare, Science, 316, 1866-1869, doi:10.1126/science.1140170, 2007.

Kurmis, V. and Sucoff, E.: Population density and height distribution of Corylus cornuta in undisturbed forests of Minnesota, Can. J. Bot., 67, 2409-2413, doi:10.1139/b89-308, 1989.

MacKenzie, M. D., Luca, T. H., and Sala, A.: Fire exclusion and nitrogen mineralization in low elevation forests of western Montana, Soil Biol. Biochem., 38, 952-961, doi:10.1016/j.soilbio.2005.08.008, 2006.

Mann, H. B.: Non-parametric test against trend, Econometrica, 13, 245-249, doi:10.1080/10629360600564924, 1945.

McLauchlan, K. K. and Craine, J. M.: Species-specific trajectories of nitrogen isotopes in Indiana hardwood forests, USA, Biogeosciences, 9, 867-874, doi:10.5194/bg-9-867-2012, 2012.

McLauchlan, K. K., Craine, J. M., Oswald, W. W., Leavitt, P. R., and Likens, G. E.: Changes in nitrogen cycling during the past century in a northern hardwood forest, P. Natl. Acad. Sci. USA, 104, 7466-7470, doi:10.1073/pnas.0701779104, 2007.

McLauchlan, K. K., Williams, J. J., Craine, J. M., and Jeffers, E. S.: Changes in global nitrogen cycling during the Holocene epoch, Nature, 495, 352-355, doi:10.1038/nature11916, 2013 a.

McLauchlan, K. K., Lascu, I., Myrbo, A., and Leavitt, P. R.: Variable ecosystem response to climate change during the Holocene in northern Minnesota, USA, Geol. Soc. Am. Bull., 125, 445452, doi:10.1130/B30737.1, 2013b.

Minnesota Department of Natural Resources: Itasca State Park management plan, http://files.dnr.state.mn.us/parks_trails/ mgmtplans/itasca_plan.pdf (last access: 13 February 2015), 1998.

National Atmospheric Deposition Program: 2013 Annual Summary, http://nadp.sws.uiuc.edu/lib/data/2013as.pdf (last access: 21 April 2015), 2013.

National Climatic Data Center: Climatography of the United States, 1971-2000, http://www.ncdc.noaa.gov/DLYNRMS/ dnrm?coopid=214106 (last access: 23 April 2015), 2000.

Nave, L. E., Gough, C. M., Maurer, K. D., Bohrer, G., Hardiman, B. S., Moine, M. Le Munoz, A. B., Nadelhoffer, K. J., Sparks, J. P., Strahm, B. D., Vogel, C. S., and Curtis, P. S.: Disturbance and the resilience of coupled carbon and nitrogen cycling in a northern temperate forest, J. Geophys. Res-Biogeo., 116, G04016, doi:10.1029/2011JG001758, 2011.

Pardo, L. H., Hemond, H. F., Montoya, J. P., Fahey, T. J., and Sicama, T. G.: Response of the natural abundance of N-15 in forest soils and foliage to high nitrate loss following clear-cutting, Can. J. Forest., 32, 1126-1136, doi:10.1139/x02-041, 2002.

Pardo, L. H., Templer, P. H., Goodale, C. L., Duke, Duke, S., Groffman, P. M., Adams, M. B., Boeckx, P., Boggs, J., Campbell,
J., Colman, B., Compton, J., Emmett, B., Gundersen, P., Kjønaas, Lovett, G., Mack, M., Magill, A., Mbila, M., Mitchell, M. J., McGee, G., McNulty, S., Nadelhoffer, K., Ollinger, S., Ross, D., Rueth, H., Rustad, L., Schaberg, P., Schiff, S., Schleppi, P., Spoelstra, J., and Wessel, W.: Regional assessment of N saturation using foliar and root delta N-15, Biogeochemistry, 80, 143171, doi:10.1007/s10533-006-9015-9, 2006.

Peet, R. K.: Twenty-six years of change in a Pinus strobus, Acer saccharum forest, Lake Itasca, Minnesota, B. Torrey Bot. Club, 111, 61-68, doi:10.3375/043.029.0208, 1984.

Pettitt, A. N.: A nonparametric approach to the changepoint problem, Applied Statistician, 28, 126-135, doi:10.2307/2346729, 1979.

Poulson, S. R., Chamberlian, C. P., and Friedland, A. J.: Nitrogen isotope variation of tree rings as a potential indicator of environmental change, Chem. Geol., 125, 307-315, doi:10.1016/00092541(95)00097-6, 1995.

Rebstock, G. A.: Climatic regime shifts in decadal-scale variability in calanoid copepod populations off southern California, Glob. Change Biol., 8, 71-89, doi:10.1046/j.1365-2486.2002, 2002.

Santoro, A. E., Lombardero, M. J., Ayres, M. P., and Ruel, J. J.: Interactions between fire and bark beetles in an old growth pine forest, Forest Ecol. Manag., 5148, 1-10, doi:10.1016/S03781127(00)00389-3, 2001.

Sen, P. K.: Estimates of the regression coefficient based on Kendall's tau, J. Am. Stat. Assoc., 63, 1379-1389, doi:10.1080/01621459.1968.10480934, 1968.

Silver, E. J., Fraver, S., D'Amato, A. W., Aakala, T., and Palik, B. J.: Long-term mortality rates and spatial patterns in an old-growth Pinus resinosa forest, Can. J. Forest., 43, 809-816, doi:10.1139/cjfr-2013-0139, 2013.

Smithwick, E. A. H., Turner, M. G., Mack, M. C., and Chapin, F. S.: Postfire Soil N Cycling in Northern Conifer Forests Affected by Severe, Stand-Replacing Wildfires, Ecosystems, 8, 163-181, 2005.

Spurr, S. H.: The forest of Itasca in the Nineteenth Century as Related to Fire. Ecology, 35, 21-25, doi:10.2307/1931399, 1954.

Stock, W. D., Bourke, L., and Froend, R. H: Dendroecological indicators of historical responses of pines to water and nutrient availability on a superficial aquifer in south- western Australia, Forest Ecol. Manag., 264, 108-114, doi:10.1016/j.foreco.2011.09.033. 2012.

Tappeiner, J. C. and Alm, A. A.: Undergrowth vegetation effects on the nutrient content of litterfall and soils in red pine and birch stands in northern Minnesota, Ecology, 56, 1193-1200, doi:10.2307/1936159, 1975

Vitousek, P. M., Mooney, H. A., Lubchneco, J., and Melillo, J. M.: Human Domination of Earth's Ecosystems, Science, 277, 494499, doi:10.1126/science.277.5325.494, 1997.

Wang, Q., Zhong, M., and Wang, S.: A meta-analysis on the response of microbial biomass, dissolved organic matter, respiration, and $\mathrm{N}$ mineralization in mineral soil to fire in forest ecosystems, Forest Ecol. Manag., 271, 91-97, doi:10.3389/fmicb.2013.00163, 2012.

Webb, S. L.: Contrasting windstorm consequences in two forests, Itasca State Park, Minnesota, Ecology, 70, 1167-1180, 1989.

Wolfe, A. P., W. O. Hobbs, H. H. Birks, J. P. Briner, S. U. Holmgren, O. Ingolfsson, S. Kaushal, G. H. Miller, M. Pagani, J. E. Saros, and R. Vinebrooke.: Stratigraphic expressions of the Holocene- 
Anthropocene transition revealed in sediments from remote lakes, Earth-Sci. Revs., 116, 17-34, doi:10.2307/1941384, 2013.
Zenner, E. K. and Peck, J. E.: Characterizing structural conditions in mature managed red pine: Spatial dependency of metrics and adequacy of plot site, Forest Ecol. Manag., 255, 3051-3062, doi:10.1016/j.foreco.2008.09.006, 2009. 